\title{
Autologous bone marrow aspirate concentrate (BMAC) for treatment of keratocystic odontogenic tumour (KCOT) - a case report
}

\author{
Manimaran Kanakaraj ${ }^{1}$, Sangeetha Manoharan ${ }^{1}$, Sivashankaran Srinivas ${ }^{2}$, Marudhamani Chinnannan $^{1}$, \\ Avinash Gandhi Devadas $^{3,4}$, Rashmi Jain ${ }^{4}$, Sathish Muthu ${ }^{4,5,6}$, Madhan Jeyaraman ${ }^{4,5,7} \wedge$ \\ ${ }^{1}$ Department of Oral and Maxillofacial Surgery, KSR Institute of Dental Sciences and Research, Tiruchengode, Tamil Nadu, India; ${ }^{2}$ Department \\ of Oral and Maxillofacial Surgery, Align Dental and Prashanth Hospitals, Chennai, Tamil Nadu, India; ${ }^{3}$ Scientific Co-ordinator, Mother Cell \\ Regenerative Center, Trichy, Tamil Nadu, India; ${ }^{4}$ Indian Stem Cell Study Group (ISCSG) Association, Lucknow, Uttar Pradesh, India; ${ }^{5}$ Research \\ Scholar, Department of Biotechnology, School of Engineering and Technology, Sharda University, Greater Noida, Uttar Pradesh, India; ${ }^{6}$ Department \\ of Orthopaedics, Government Medical College \& Hospital, Dindigul, Tamil Nadu, India; ${ }^{7}$ Department of Orthopaedics, School of Medical Sciences \\ and Research, Sharda University, Greater Noida, Uttar Pradesh, India \\ Correspondence to: Dr. Madhan Jeyaraman. Indian Stem Cell Study Group (ISCSG) Association, Lucknow, Uttar Pradesh 226010, India. \\ Email: madhanjeyaraman@gmail.com.
}

\begin{abstract}
Management of keratocystic odontogenic tumor (KCOT) has always remained a conundrum due to its aggressive behavior, indicating wide resection. Achieving an esthetically and functionally acceptable reconstruction remains a challenge. Herein, we present a novel and less invasive technique for the treatment of KCOT. A 55-year-old female presenting with pain in the lower jaw for the past 3 months was diagnosed with a large KCOT extending from 35 to 47 region. CT images revealed buccal and lingual cortical bone erosion. Management was done in two stages: cyst curettage and chemical cauterization, followed by application of Bone Marrow Aspirate Concentrate (BMAC) with a delay of two months, to increase the thickness of eroded cortical bone. On follow-up at one year, ossification of the defect was observed. BMAC is a cocktail of mesenchymal stromal cells, hematopoietic stem cells, fibroblasts, mononuclear cells, macrophages, endothelial cells, progenitor cells, growth factors and cytokines. BMAC cocktail provide an anti-inflammatory, anti-fibrotic, anti-apoptotic, and immunomodulatory environment. Autologous platelet rich plasma provides various growth factors (TGF- $\beta$, PDGF, EGF, HGF, NGF, IGF-1) and cytokines. Addition of PRP in BMAC cocktail enhance the regeneration of tissues, where PRP act as a functional regenerative scaffold for cell integration, proliferation, and differentiation that can expedite macroscale musculoskeletal tissue healing. Autologous BMAC with corticocancellous bone acts as an osteoconductive scaffold capable of regenerating the large bone defect created by the curettage of KCOT.
\end{abstract}

Keywords: Autologous bone marrow aspirate concentrate (autologous BMAC); keratocystic odontogenic tumor (KCOT); mandibular regeneration; case report

Received: 23 October 2020; Accepted: 29 April 2021; Published: 16 August 2021.

doi: $10.21037 /$ sci-2020-059

View this article at: http://dx.doi.org/10.21037/sci-2020-059

\section{Introduction}

The keratocystic odontogenic tumor (KCOT) is notorious for significant morbidity to the patient upon wide resection and management of the bone defect remains a challenge to the operating surgeon (1). Fragile cyst walls with a propensity towards cortical breach and satellite cysts

^ ORCID: Madhan Jeyaraman, 0000-0002-9045-9493; Sathish Muthu, 0000-0002-7143-4354; Rashmi Jain, 0000-0003-4386-6755. 


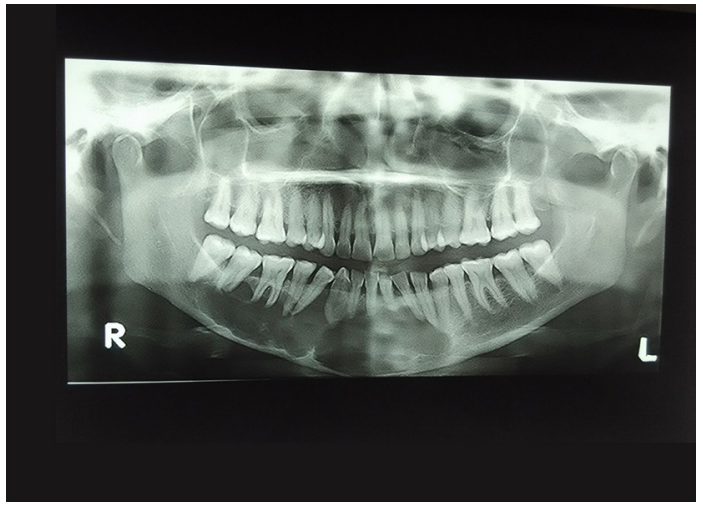

Figure 1 Preoperative panoramic view showing KCOT from 34 to 47. KCOT, keratocystic odontogenic tumour.
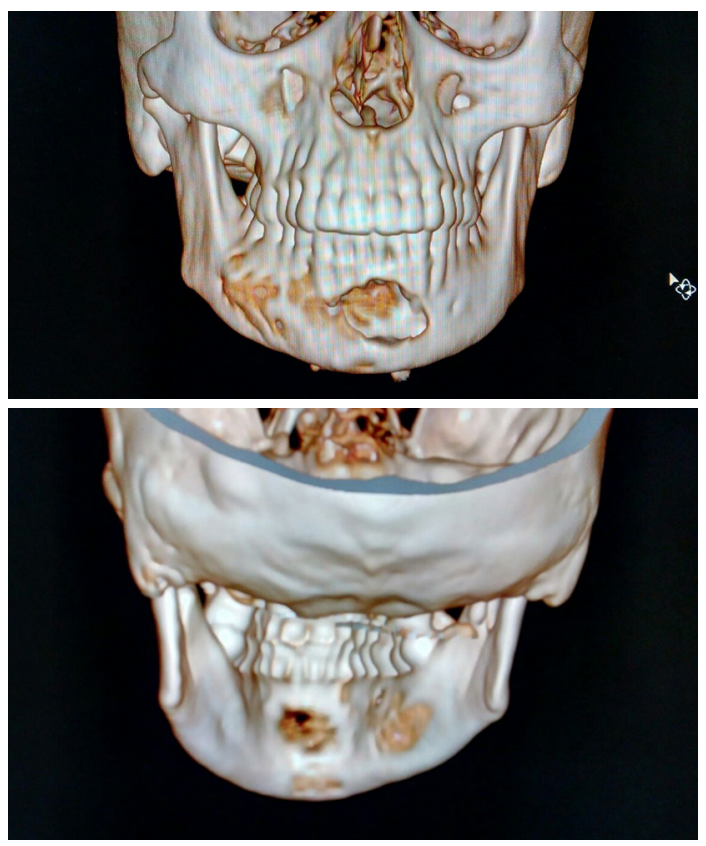

Figure 2 Preoperative CT showing perforation of buccal and lingual cortical plate.

contribute to its high recurrence $(2,3)$. Traditional methods involved in the management of KCOT include enucleation, marsupialization, chemical cauterization, marginal resection, or en-block resection depending upon the size and location of the tumor (4-7). Reconstruction of large defects always remained a challenge in this scenario. Considering the potentiality of autologous bone marrow aspiration concentrate (BMAC) in varied medical fields, an innovative approach to deal with KCOT using BMAC was devised.
Autologous BMAC has all the elements needed for bone regeneration like the Bone Marrow derived Mesenchymal Stem Cells, platelets, soluble factors, and mononucleated cells (8). The bone marrow concentrates were reported to successfully regenerate segmental mandibular defects up to $15 \mathrm{~cm}$ in length $(9,10)$. We present the following case in accordance with the CARE reporting checklist (available at http://dx.doi.org/10.21037/sci-2020-059).

\section{Case presentation}

A 55 years old female patient presented with a chief complaint of pain in the lower jaw region for the past 3 months. The medical history of the patient was unremarkable. Clinical examination revealed no evidence of swelling or lymphadenopathy. Panoramic imaging revealed a large, radiolucent lesion of size $10 \times 4 \mathrm{~cm}$ with well-defined scalloped margins extending from the distal aspect of 47 to the distal aspect of 35 regions with no evidence of root resorption. The inferior border of the mandible was thin but intact (as shown in Figure 1). Computed tomographic (CT) images with three-dimensional reconstruction revealed a well-defined multilocular cystic lesion with buccal and lingual cortical bone erosion (as shown in Figure 2). Aspiration was negative.

Treatment was done as a two-stage procedure.

Stage 1: the patient was operated on under general anesthesia. A vestibular incision was made from the right second molar to the left canine region. A full-thickness mucoperiosteal flap was elevated. A bony window opened near the first molar and the cyst was entered through the window. Cystic lining curettage and chemical cauterization was done using Carnoy's solution (60\% ethanol, $30 \%$ chloroform, and $10 \%$ glacial acetic acid) for one minute. The cystic cavity was thoroughly irrigated with saline solution. The cystic cavity was loosely packed with iodoform gauze of length $25 \mathrm{~cm}$ with one end outside. The incision closed using 3-0 vicryl with the bone window was kept open. The gauze piece was removed after 4 days. Appropriate analgesics and antibiotics were prescribed. The specimen was sent for histopathological examination. The tissue sent for HPE was diagnosed as KCOT. The postoperative OPG was performed after one month after the stage 1 procedure (as shown in Figure 3).

Stage 2: this procedure was done after 2 months after the index surgery. Bone marrow was aspirated following all aseptic precautions. The patient was operated on under general anesthesia in a prone position. A stab incision was 


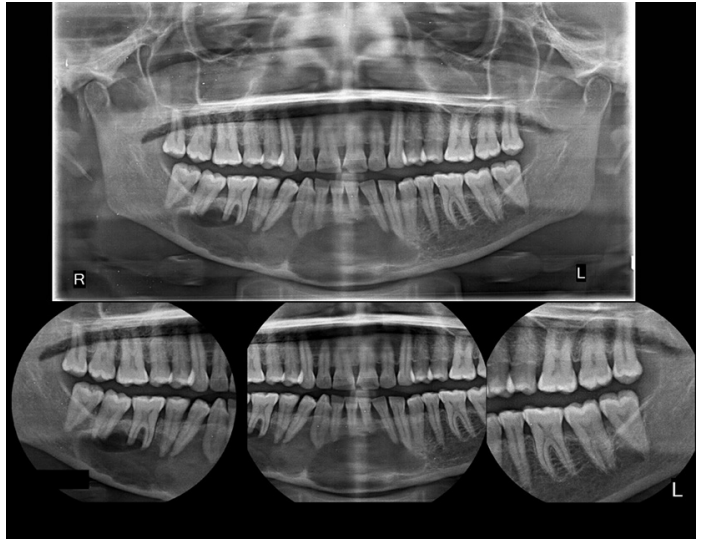

Figure 3 Postoperative OPG after one month after Stage 1 procedure.

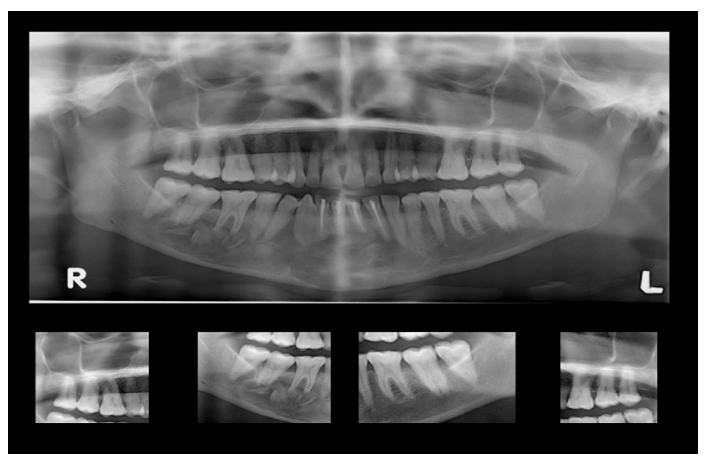

Figure 4 Immediate post operative OPG after stage 2 procedure.

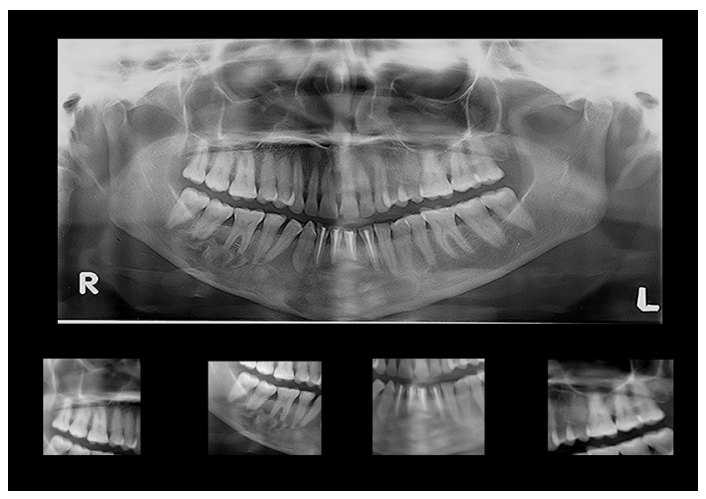

Figure 5 Postoperative OPG after 2 months.

made in the posterior iliac crest. A bone marrow aspiration needle (11G, Precise, Leur lock) was inserted into the marrow cavity. Marrow collected from multiple sites at different angulations using a $50 \mathrm{~mL}$ syringe preloaded with

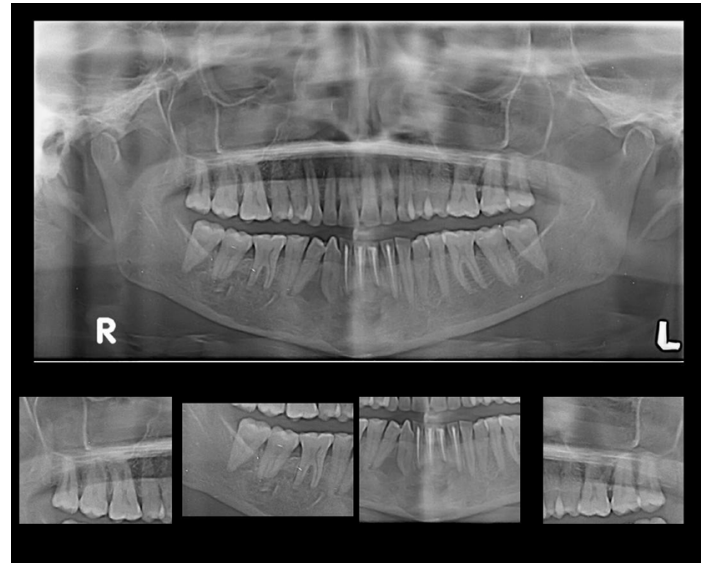

Figure 6 Postoperative OPG after 4 months showing partial filling of defect by newly regenerated bone.

$1 \mathrm{~mL}$ heparin to prevent coagulation. The aspirated bone marrow $(60 \mathrm{~mL})$ was mixed with ACD solution (Acid Citrate Dextrose) in a blood transfer tray in a ratio of 8:1 respectively. Biosafe Sepax (S-100) processing kits were used following standard protocols. The final BMAC obtained was $10 \mathrm{~mL}$.

A vestibular incision was made from the right second molar to the left canine region. A full-thickness mucoperiosteal flap was elevated. The bony window was already present near the first molar region and a new bony window was created in the left mandibular canine region. The residual cystic lining was removed. All the cystic walls were made completely free from the lining. The cystic defect was filled with autogenous corticocancellous bone mixed with $7 \mathrm{~mL}$ of BMAC. Wound closure was done using 3-0 vicryl. The remaining $3 \mathrm{~mL}$ of BMAC was injected inside the defect at multiple sites. The immediate postoperative OPG was done as shown in Figure 4.

The patient was serially followed for 2 years (as shown in Figures 5,6). Lower lip numbness was noted on the right side for 6 months post-operatively. Recurrence of the lesion was noted at 2 years in the inter-radicular region between 43 and 44 (as shown in Figure 7). Extraction of 43 and 44 was done along with cyst enucleation and platelet-rich plasma (PRP) application. PRP augments bone regeneration by providing various growth factors. The patient remained asymptomatic until 4 years of follow-up with regenerated bone in the operated site without any signs of recurrence (as shown in Figure 8).

All procedures performed in studies involving human participants were in accordance with the ethical standards of the institutional and/or national research committee(s) and 


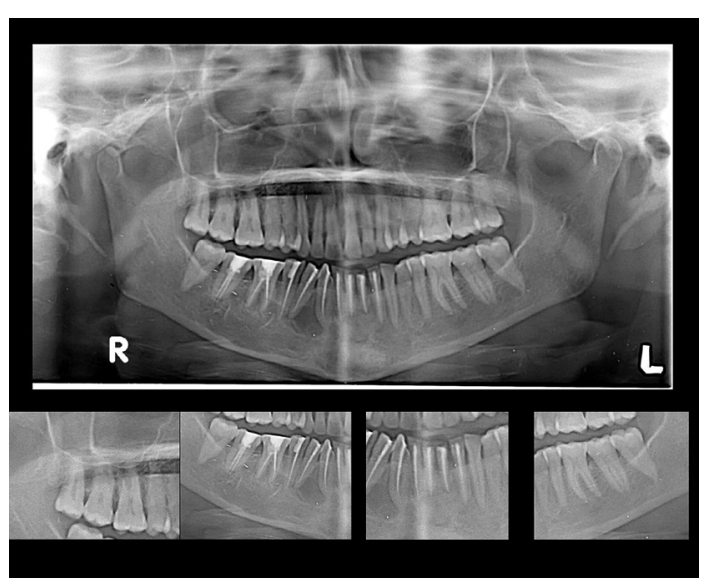

Figure 7 Follow-up after 24 months shows recurrence in interradicular region between 43 and 44 .

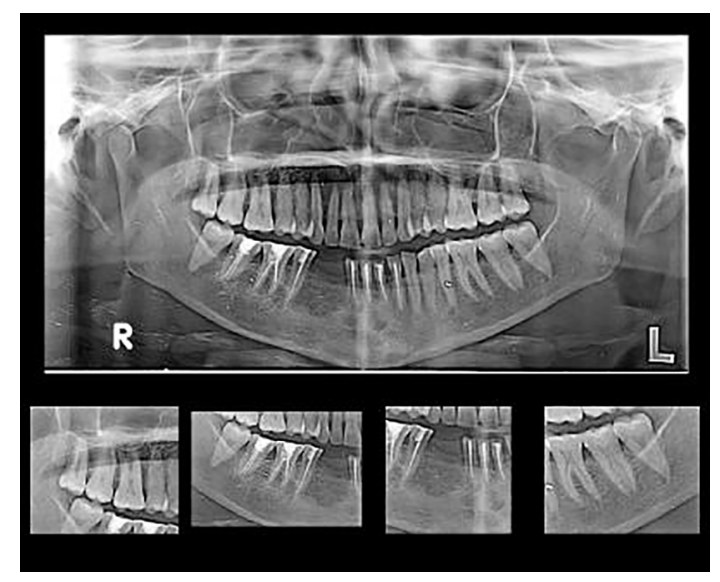

Figure 8 Postoperative OPG 6 months after extraction of 43 and 44 followed by PRP placement.

with the Helsinki Declaration (as revised in 2013). Written informed consent was obtained from the patient.

\section{Discussion}

Odontogenic keratocyst (OKC) was renamed as KCOT considering the neoplastic nature of the lesion (11). Being a benign developmental odontogenic tumor, KCOT has many distinguishing features such as its locally aggressive nature and high recurrence rate $(12,13)$. It represents $4-12 \%$ of all odontogenic cysts (14). Although the lesion is prevalent among all ages, it has a peak incidence in the second and third decades of life with a predilection for white males (15). Mandible remains the most common site of origin, of which half of them arise from the angle of the mandible (16). Although KCOT remains an intra-osseous lesion, peripheral lesions have also been reported. The involvement of the gingival or alveolar mucosa of the canine and premolar region is seen in the majority of the cases.

Although keratocystic tumors are diagnosed incidentally, they also present with pain and swelling. Imaging of the lesion reveals unilocular radiolucencies with well-defined margins $(17,18)$. In the case of large lesions, the lesion is multi-loculated with scalloped borders as in our case. The cyst is often associated with an impacted tooth making dentigerous cyst a potential differential to this condition.

Multiple treatment methods have been proposed and debated for the management of KCOT. Minimizing the risk of recurrence and morbidity of resection remains a major challenge for any proposed line of management. Various modalities of treatment ranging from decompression through enucleation alone with or without curettage to complete resection have been employed in their management. Shear et al. reported the recurrence rate of KCOT to range from $3 \%$ to $60 \%$ (19).

Factors responsible for the recurrence of the lesion include its size, location, associated infection, teeth or mucosal involvement, and association with the Gorlin syndrome (20). Hence, ideal management is tailor-made as per the presentation on a case-by-case basis. Browne confirmed the higher recurrence rate of these KCOTs from other cysts and suggested that it was caused by an inherent property of the cysts themselves rather than the technique of removal (21). Many theories have been stated for the increased incidence of recurrence: delicate cystic lining which makes it susceptible to leave remnants after surgical removal, satellite cysts, or daughter cysts (22).

The conventional method for the treatment of most KCOTs is surgical enucleation, and for larger cysts, marsupialization is often later followed by enucleation. Since the lining of the cyst is thin and delicate which often leads to recurrence, the above-mentioned methods were not sufficient to prevent a recurrence. Adjunctive surgical treatment has been recommended by Ghali such as removal of the peripheral bone or en-bloc resection (23). The aforementioned methods are radical and associated morbidity is even higher. It often requires reconstruction for the restoration of function and esthetics. Other adjunctive treatments such as cryotherapy with liquid nitrogen were proposed by Schmidt (24) and irrigation of the curetted cavity with Carnoy's solution after enucleation was suggested by Stoelinga (25) to address the residual 
tumor cells to prevent a recurrence. We used Carnoy's solution as an adjuvant in our case.

Bone marrow aspirate concentrate (BMAC) enhances bone regeneration when the defect is being transplanted with progenitor cells (26). Enhanced osteogenesis is due to the presence of concentrated mononuclear cells in the BMAC (27). The dynamic migration of MSCs to the defect site is a time-, dose- and CXCR4-dependent process (28). Various studies demonstrated the beneficial role of BMAC in bone healing (29,30). Autologous mesenchymal stem cells when used with osteoconductive scaffold acts as a graft material with high regenerative capacity. Talaat $e t$ al. used autologous BMAC and concentrated growth factors for bone regeneration after the enucleation of mandibular pathologic lesions. Accelerated bone regeneration and improved bone density were observed (31). Manimaran et al. treated two cases of osteoradionecrosis (ORN) with autologous BMAC and had excellent functional outcomes without the morbidity of radical surgery (32).

Potential advantages in BMAC include its technical simplicity in harvesting without the risk of allogeneic disease transmission (33). Recent studies have highlighted that MSCs are capable of regenerating large bone defects when used in combination with bone substitutes $(34,35)$. PRP, can be an excellent addition to MSCs and freeze-dried bone grafts. MSCs express receptors for the growth factors contained in the PRP and in vitro studies have shown that the addition of PRP promotes MSC proliferation. Autologous BM-MSCs and PRP may lead to increased bone regeneration and reduced healing time $(36,37)$.

\section{Conclusions}

The KCOT has been an enigmatic subject matter among surgeons over many decades concerning its origination, the pattern of growth, clinical presentation, and modality of treatment. Autologous BMAC with corticocancellous bone acts as an osteoconductive scaffold capable of regenerating the large bone defect created by the curettage of OKC. The ascertainable advantages of our protocol in the management of KCOT include (I) erasure of lesion, (II) regeneration of large bone defect due to curettage, (III) optimal healing at the earliest, and (IV) preservation of function and shape of the jaw.

\section{Acknowledgments}

Funding: None.

\section{Footnote}

Reporting Checklist: The authors have completed the CARE reporting checklist. Available at http://dx.doi.org/10.21037/ sci-2020-059

Conflicts of Interest: All authors have completed the ICMJE uniform disclosure form (available at http://dx.doi. org/10.21037/sci-2020-059). The authors have no conflicts of interest to declare.

Ethical Statement: The authors are accountable for all aspects of the work in ensuring that questions related to the accuracy or integrity of any part of the work are appropriately investigated and resolved. All procedures performed in studies involving human participants were in accordance with the ethical standards of the institutional and/or national research committee(s) and with the Helsinki Declaration (as revised in 2013). Written informed consent was obtained from the patient.

Open Access Statement: This is an Open Access article distributed in accordance with the Creative Commons Attribution-NonCommercial-NoDerivs 4.0 International License (CC BY-NC-ND 4.0), which permits the noncommercial replication and distribution of the article with the strict proviso that no changes or edits are made and the original work is properly cited (including links to both the formal publication through the relevant DOI and the license). See: https://creativecommons.org/licenses/by-nc-nd/4.0/.

\section{References}

1. Grasmuck EA, Nelson BL. Keratocystic odontogenic tumor. Head Neck Pathol 2010;4:94-6.

2. Chi AC, Owings JR Jr, Muller S. Peripheral odontogenic keratocyst: report of two cases and review of the literature. Oral Surg Oral Med Oral Pathol Oral Radiol Endod 2005;99:71-8.

3. Johnson NR, Batstone MD, Savage NW. Management and recurrence of keratocystic odontogenic tumor: a systematic review. Oral Surg Oral Med Oral Pathol Oral Radiol 2013;116:e271-6.

4. Blanas N, Freund B, Schwartz M, et al. Systematic Review of treatment and prognosis in the odontogenic keratocyst. Oral Surg Oral Med Oral Pathol Oral Radiol Endod 2000;90:553-8.

5. Borrás-Ferreres J, Sánchez-Torres A, Alberdi-Navarro 
$\mathrm{J}$, et al. Therapeutic management of the odontogenic keratocyst. An energetic approach with a conservative perspective and review of the current therapeutic options. J Clin Exp Dent 2020;12:e794-9.

6. Nath P, Menon S, Sham ME, et al. Conservative Management of Odontogenic Keratocyst in a Tertiary Hospital. Ann Maxillofac Surg 2020;10:122-6.

7. Sharif $\mathrm{FNj}$, Oliver $\mathrm{R}$, Sweet $\mathrm{C}$, et al. Interventions for the treatment of keratocystic odontogenic tumours (KCOT, odontogenic keratocysts $(\mathrm{OKC})$ ). Cochrane Database Syst Rev 2010;(9):CD008464.

8. Kitoh H, Kitakoji T, Tsuchiya H, et al. Transplantation of marrow-derived mesenchymal stem cells and plateletrich plasma during distraction osteogenesis--a preliminary result of three cases. Bone 2004;35:892-8.

9. Lee J, Sung HM, Jang JD, et al. Successful reconstruction of 15 -cm segmental defects by bone marrow stem cells and resected autogenous bone graft in central hemangioma. J Oral Maxillofac Surg 2010;68:188-94.

10. Ma J, Both SK, Yang F, et al. Concise review: cell-based strategies in bone tissue engineering and regenerative medicine. Stem Cells Transl Med 2014;3:98-107.

11. Nayak MT, Singh A, Singhvi A, et al. Odontogenic keratocyst: What is in the name? J Nat Sci Biol Med 2013;4:282-5.

12. Borghesi A, Nardi C, Giannitto C, et al. Odontogenic keratocyst: imaging features of a benign lesion with an aggressive behaviour. Insights Imaging 2018;9:883-97.

13. Chirapathomsakul D, Sastravaha P, Jansisyanont P. A review of odontogenic keratocysts and the behavior of recurrences. Oral Surg Oral Med Oral Pathol Oral Radiol Endod 2006;101:5-9.

14. Johnson NR, Gannon OM, Savage NW, et al. Frequency of odontogenic cysts and tumors: a systematic review. J Investig Clin Dent 2014;5:9-14.

15. Sánchez-Burgos R, González-Martín-Moro J, PérezFernández E, et al. Clinical, radiological and therapeutic features of keratocystic odontogenic tumours: a study over a decade. J Clin Exp Dent 2014;6:e259-64.

16. Eryilmaz T, Ozmen S, Findikcioglu K, et al. Odontogenic keratocyst: an unusual location and review of the literature. Ann Plast Surg 2009;62:210-2.

17. MacDonald D, Gu Y, Zhang L, et al. Can clinical and radiological features predict recurrence in solitary keratocystic odontogenic tumors? Oral Surg Oral Med Oral Pathol Oral Radiol 2013;115:263-71.

18. Harmon M, Arrigan M, Toner M, et al. A radiological approach to benign and malignant lesions of the mandible.
Clin Radiol 2015;70:335-50.

19. Shear M, Speight PM. Odontogenic keratocyst. In: Shear M, Speight PM editor(s). Cysts of the oral and maxillofacial regions. 4th Edition. Oxford: Blackwell Munksgaard, 2007:6-58.

20. Tarakji B, Baroudi K, Hanouneh S, et al. Possible recurrence of keratocyst in nevoid basal cell carcinoma syndrome: A review of literature. Eur J Dent 2013;7:S126-34.

21. Browne RM. The odontogenic keratocyst. Histological features and their correlation with clinical behaviour. $\mathrm{Br}$ Dent J 1971;131:249-59.

22. Singh M, Gupta KC. Surgical treatment of odontogenic keratocyst by enucleation. Contemp Clin Dent 2010;1:263-7.

23. Ghali GE, Connor MS. Surgical management of the odontogenic keratocyst. Oral Maxillofac Surg Clin North Am 2003;15:383-92.

24. Schmidt BL. The use of liquid nitrogen cryotherapy in the management of the odontogenic keratocyst. Oral Maxillofac Surg Clin North Am 2003;15:393-405.

25. Stoelinga PJ. The treatment of odontogenic keratocysts by excision of the overlying, attached mucosa, enucleation, and treatment of the bony defect with carnoy solution. J Oral Maxillofac Surg 2005;63:1662-6.

26. Granero-Moltó F, Weis JA, Miga MI, et al. Regenerative effects of transplanted mesenchymal stem cells in fracture healing. Stem Cells 2009;27:1887-98.

27. Hernigou P, Poignard A, Beaujean F, et al. Percutaneous autologous bone-marrow grafting for nonunions. Influence of the number and concentration of progenitor cells. J Bone Joint Surg Am 2005;87:1430-7.

28. Wynn RF, Hart CA, Corradi-Perini C, et al. A small proportion of mesenchymal stem cells strongly expresses functionally active CXCR4 receptor capable of promoting migration to bone marrow. Blood 2004;104:2643-5.

29. Jäger M, Jelinek EM, Wess KM, et al. Bone marrow concentrate: a novel strategy for bone defect treatment. Curr Stem Cell Res Ther 2009;4:34-43.

30. Jäger $M$, Herten $M$, Fochtmann $U$, et al. Bridging the gap: bone marrow aspiration concentrate reduces autologous bone grafting in osseous defects. J Orthop Res 2011;29:173-80.

31. Talaat WM, Ghoneim MM, Salah O, et al. Autologous Bone Marrow Concentrates and Concentrated Growth Factors Accelerate Bone Regeneration After Enucleation of Mandibular Pathologic Lesions. J Craniofac Surg 2018;29:992-7. 
32. Manimaran K, Sankaranarayanan S, Ravi VR, et al. Treatment of osteoradionecrosis of mandible with bone marrow concentrate and with dental pulp stem cells. Ann Maxillofac Surg 2014;4:189-92.

33. Chahla J, Mannava S, Cinque ME, et al. Bone Marrow Aspirate Concentrate Harvesting and Processing Technique. Arthrosc Tech 2017;6:e441-5.

34. De Kok IJ, Drapeau SJ, Young R, et al. Evaluation of mesenchymal stem cells following implantation in alveolar sockets: a canine safety study. Int J Oral Maxillofac Implants 2005;20:511-8.

35. Dallari D, Fini M, Stagni C, et al. In vivo study on the

doi: 10.21037/sci-2020-059

Cite this article as: Kanakaraj M, Manoharan S, Srinivas S, Chinnannan M, Devadas AG, Jain R, Muthu S, Jeyaraman M. Autologous bone marrow aspirate concentrate (BMAC) for treatment of keratocystic odontogenic tumour (KCOT) — a case report. Stem Cell Investig 2021;8:16. healing of bone defects treated with bone marrow stromal cells, platelet-rich plasma, and freeze-dried bone allografts, alone and in combination. J Orthop Res 2006;24:877-88.

36. Gianakos A, Ni A, Zambrana L, et al. Bone Marrow Aspirate Concentrate in Animal Long Bone Healing: An Analysis of Basic Science Evidence. J Orthop Trauma 2016;30:1-9.

37. Shin HS, Kim MS, Kim BH, et al. Reconstruction of Mandibular Defects With Bone Marrow-Derived Stem Cells in Odontogenic Myxoma. J Craniofac Surg 2020;31:e236-9. 